\title{
Synthesis, Characterizaiton of Cuo Nano-Rod for Supercapacitor Applications
}

\author{
Govindaswamy Padmapriyaa, Pandian Paulrajb, Ayyar Manikandanc
}

\begin{abstract}
A novel approach solvothermal synthesis method has been utilized to prepare $\mathrm{CuO}$ nanorods for electrochemical capacitors. A new method of synthesis has been adopted for the synthesis of $\mathrm{CuO}$ nanostructures. Structural, morphological features of the prepared material were studied by XRD and SEM respectively. Electrochemical supercapacitive performances of the modified electrode material were also analyzed by electrochemical workstation in three-electrode system. This material found to exhibit pesudocapacitive behavior with high capacitance of $135.23 \mathrm{~F} / \mathrm{g}$ at the prevalent density of $1 \mathrm{~A} / \mathrm{g}$ in $1 \mathrm{M} \mathrm{Na2SO4}$ electrolyte solution, proving a suitable candidate electrode material for supercapacitor applications.
\end{abstract}

Key words: Metal oxide, Morphology, Electrochemical Properties, $\mathrm{CuO}$ nanorod

\section{INTRODUCTION}

The power requirements for a number of portable electronic devices have increased rapidly in modern years and have excelled the capacity of batteries [1-3]. Supercapacitor also known as electrochemical capacitor has been a subject of interest to many majorities to apply in whole research $[4,5]$. The pursuance of an electrochemical supercapacitor led voltage based on power densities and energy [6].

The supercapacitor based on electrochemical double-layer capacitance (EDLC) and psudocapacitor capacitance [7]. Carbon and its activated charcoal, carbon arogels, and nanotubes are frequently utilized as electrode [8]. Another class of supercapacitor is based on pseudocapacitance that stores and releases energy [9].

In recent years, metal oxides ( $\mathrm{NiO} 2$ and $\mathrm{CuO})$ activated carbon composite materials have been prepared as potential electrode materials [10]. Among oxides, Copper oxide (CuO) has promising characteristic over the supercapacitor material as well [10-12]. $\mathrm{CuO}$ is a well-known material its characteristic in density $(650 \mathrm{~A} / \mathrm{g})$ and binding energy a [13-15] and it has high emission capability at RT and tranperent [16-20]. Because of its good eco-friendly nature, researchers have begun to study $\mathrm{CuO}$ to be a promising

Revised Manuscript Received on October 22, 2019.

Govindaswamy Padmapriya ${ }^{b}$ Department of Chemistry, Faculty of Arts \& Science,Bharath Institution Of Higher Education And Research TamilNadu,India.Email: ppstminex@gmail.com

Pandian Paulraj, Assistant Professor, ${ }^{b}$ Department of Chemistry, Faculty of Arts \& Science,Bharath Institution Of Higher Education And Research TamilNadu,India.Email: paulrajp.che@bharathuniv.ac.in

Ayyar Manikandan ${ }^{b}$ Department of Chemistry, Faculty of Arts \& Science,Bharath Institution Of Higher Education And Research TamilNadu,India.Email: mkavath15@gmail.com electrode material for the supercapacitance applications [21-30]. In this article, novel method of rod-like $\mathrm{CuO}$ nanostructure. This technique is found to be very simple, template-free method when compared to the other synthesis schemes[31-35].

\section{EXPERIMENTAL METHODS}

\section{A. Material synthesis}

$\mathrm{CuO}$ was synthesized via hydrothermal method. The synthesis procedure is as follows: initially, $9 \mathrm{~g}$ of mixed hydroxides solution was prepared in a beaker by adding equimolar ratio of $\mathrm{NaOH}$ and $\mathrm{KOH}$ pellets. The homogeneous solution was then transferred into an autoclave containing a Teflon vessel and kept in a furnace for 24 hours at a constant temperature of $180{ }^{\circ} \mathrm{C}$. After completion of reaction, the autoclave containing solution was cooled down to room temperature naturally.

\section{B. Characterization}

The structure was studied by powder XRD, Rigaku miniflux (II)-c). The morphology was viewed on a SEM by using VEGA3 SBU, VGB 825111771N. The electrochemical property was analyze using $\mathrm{CHI}$ instruments. current was applied between $0.0-0.4 \mathrm{~V}(\mathrm{Ag} / \mathrm{AgCl})$.

\section{RESUltS AND DISCUSSION}

The phase structure of obtained product is depicted in Fig. 1. All the identified peaks are shown in Fig. 1 can be attributed to the hexagonal Wurtzite structure of $\mathrm{CuO}$. The XRD pattern confirms the pure $\mathrm{CuO}$ structure and further reveals that no additional peaks were noticed, which confirms the high crystanallity of the material [16].

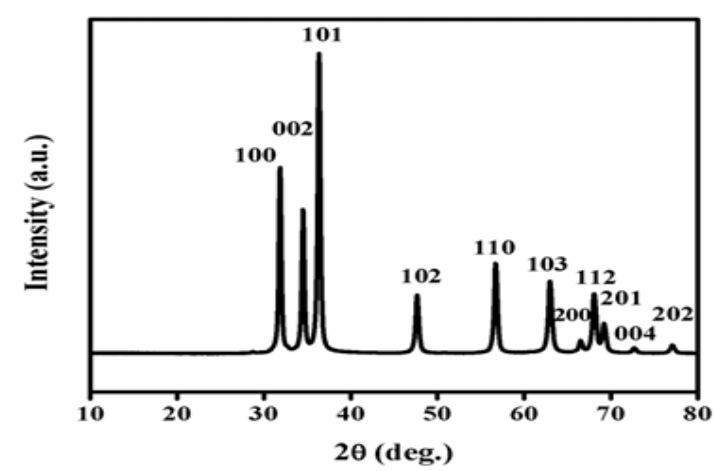

Fig. 1 XRD patterns of Pristine $\mathrm{CuO}$ nanorod 


\section{Synthesis, Characterizaiton of Cuo Nano-Rod for Supercapacitor Applications}

The average crystallite size was calculated using Debye Scherrer formula given in Eq. (1)

$$
L=\frac{0.89 \lambda}{\beta \cos \theta}
$$

---- (1)

The average crystallite size ' $L$ ' calculated from the region around $15-30 \mathrm{~nm}$.

The SEM was used to investigate the morphological changes after hydroxide treatment of $\mathrm{CuO}$ material. The aggregation of particles (or formation of larger particles) could have originated from the surface energy of $\mathrm{CuO}$ nanoparticles. The aggregation might have been occurred during the process of drying. It can be seen that uniform distribution and thus reveal the single homogeneous phase $[17,18]$.
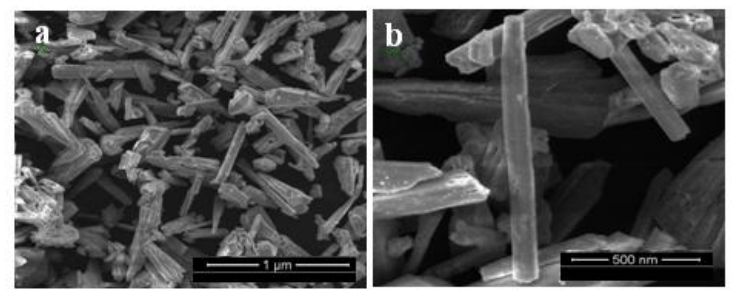

Fig. 2 SEM micrographs of $\mathrm{CuO}$ nanorod

To study the supercapacitor performances of the $\mathrm{CuO}$ and their potential application in electrochemical energy storage, cyclic voltogram (CV) analysis was carried out. Fig. 3 shows the cyclic voltammogram $(\mathrm{CV})$ of $\mathrm{CuO}$ nanostructure, which demonstrating the noticeable pseducapacitive properties. The $\mathrm{CV}$ curve is measured in $1 \mathrm{M}$ of $\mathrm{Na}_{2} \mathrm{SO}_{4}$ at potential range from 0.0 to $0.4 \mathrm{~V}$. The redox peaks observed in Fig. 3 can be ascribed to the faradic reaction of $\mathrm{CuO}$ which suggest the psedocapacitive behavior. The redox processes of $\mathrm{CuO}$ in alkaline electrolyte are based on the intercalation/deintercalation of $\mathrm{C}^{+}$ions into/ from $\mathrm{CuO}$ lattice, causing the electrochemical conservation of $\mathrm{Cu}^{2+}$ to the other valance states.

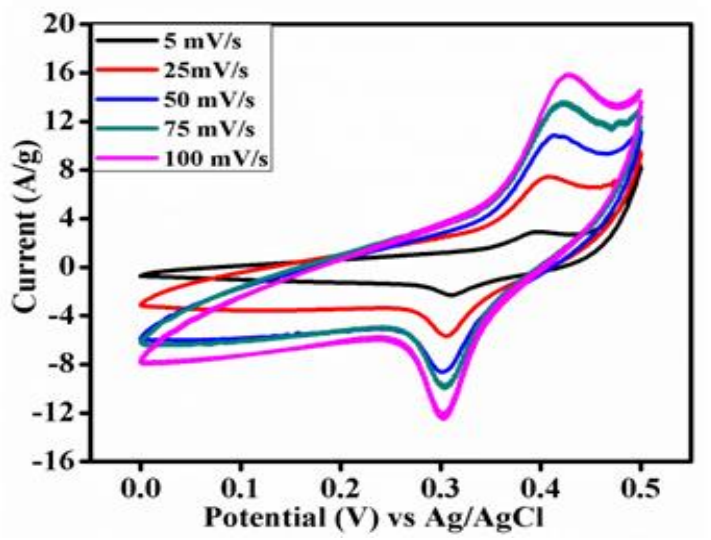

Fig. $3 \mathrm{CV}$ curves of the $\mathrm{CuO}$ electrode material at different scan rate in $1 \mathrm{M} \mathrm{Na} \mathrm{NO}_{4}$ electrolyte

\section{Conclusions}

In summary, rod-like $\mathrm{CuO}$ nanostructure prepared. The morphology of $\mathrm{CuO}$ may supply more electrochemical active sites. The modified electrode exhibited pseudocapacitive performance serve as a potential electrode material

applications. Supercapacitors have become realistic with developing more applications. It is hoped that these results can additional stimulate the necessary result and could serve as a point of departure for widening future applications.

\section{REFERENCES}

1. A. P. Subramanian, S. K. Jaganathan, A. Manikandan, K. N Pandiaraj, Gomathi N and E. Supriyanto, Recent trends in nano based drug delivery systems for efficient delivery of phytochemicals in chemotherapy, RSC Advances, 6 (2016) 48294-48314.

2. V. Muthuvignesh, V. J. Reddy, S. Ramakrishna, S. Ray, A. Ismail, M. Mandal,

A. Manikandan, S. Seal and S. K. Jaganathan, Electrospinning applications from diagnosis to treatment of diabetes, RSC Advances, 6 (2016) 83638-83655.

3. V. Muthuvignesh, S. K. Jaganathan, A. Manikandan, Nanomaterials as a game changer in the management and treatment of diabetic foot ulcers, RSC Advances, DOI: 10.1039/C6RA24590K (2016).

4. G. Padmapriya, A. Manikandan' V. Krishnasamy, Saravana Kumar Jaganathan, S. Arul Antony, Spinel $\mathrm{N}_{\mathrm{ix}} \mathrm{Z}_{\mathrm{n} 1-\mathrm{x}} \mathrm{F}_{\mathrm{e} 2 \mathrm{O} 4}(0.0 \leq \mathrm{x} \leq 1.0)$ nano-photocatalysts: Synthesis, characterization and photocatalytic degradation of methylene blue dye, Journal of Molecular Structure, 1119 (2016) 39-47.

5. B. Meenatchi, V. Renuga, A. Manikandan, Cellulose dissolution and regeneration using various imidazolium based protic ionic liquids, Journal of Molecular Liquids, Accepted Manuscript, (2016). ISSN 0617-7322.

6. V. Mary Teresita, A. Manikandan, B. Avila Josephine, S. Sujatha, S Arul Antony, Electro-magnetic properties and humidity sensing studies of magnetically recoverable $\mathrm{LaMg}_{\mathrm{x}} \mathrm{Fe}_{1-\mathrm{x}} \mathrm{O}_{3-\delta}$ perovskites nano-photocatalysts by sol-gel route, Journal of Superconductivity and Novel Magnetism, 29 (2016) 1691-1701

7. S. Jayasree, A. Manikandan, S. Arul Antony, A. M. Uduman Mohideen, C. Barathiraja, Magneto-optical and catalytic properties of recyclable spinel $\mathrm{NiAl}_{2} \mathrm{O}_{4}$ nanostructures using facile combustion methods, Journal of Superconductivity and Novel Magnetism, 29 (2016) 253-263.

8. B. Meenatchi, Velayutham Renuga, A. Manikandan, Size controlled synthesis of chalcogen and chalcogenide nanoparticles using protic ionic liquids with imidazolium cation, The Korean Journal of Chemical Engineering, 33 (2016) 934-944.

9. C. Barathiraja, A. Manikandan, A. M. Uduman Mohideen, S. Jayasree, S. Arul Antony, Magnetically recyclable spinel $\mathrm{Mn}_{\mathrm{x}} \mathrm{Ni}_{1-\mathrm{x}} \mathrm{Fe}_{2} \mathrm{O}_{4}(\mathrm{x}=$ 0.0-0.5) nano-photocatalysts: Structural, morphological and opto-magnetic properties, Journal of Superconductivity and Novel Magnetism, 29 (2016) 477-486.

10. B. Avila Josephine, A. Manikandan, V. Mary Teresita, S. Arul Antony, Fundamental study of $\mathrm{LaMg}_{\mathrm{x}} \mathrm{Cr}_{1-\mathrm{x}} \mathrm{O}_{3-\delta}$ perovskites nano-photocatalysts: Sol-gel synthesis, characterization and humidity sensing, The Korean Journal of Chemical Engineering, 33 (2016) 1590-1598.

\section{AUTHORS PROFILE}
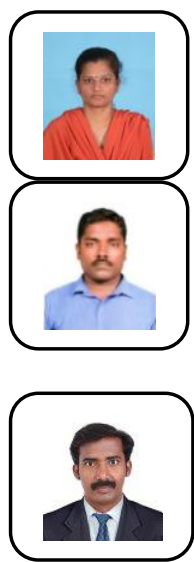

Govindaswamy Padmapriya Associate Professor ${ }^{b}$ Department of Chemistry, Faculty of Arts \& Science,Bharath Institution Of Higher Education And Research TamilNadu,India

Pandian Paulraj, Associate Professor, ${ }^{\mathrm{b}}$ Department of Chemistry, Faculty of Arts \& Science,Bharath Institution Of Higher Education And Research TamilNadu,India

Ayyar Manikandan Associate Professor bepartment of Chemistry, Faculty of Arts \& Science,Bharath Institution Of Higher Education And Research TamilNadu,India 